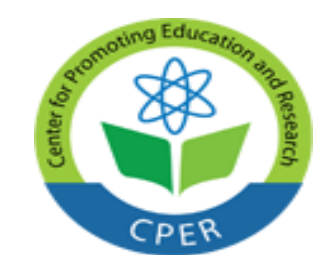

\title{
Organizational Engine for Launching Disruptive Innovation Project: Case Studies of Company A
}

\author{
Wen-Chun Tsai \\ Yi-Han Su
}

Department of Business Administration

Chung Yuan Christian University

Phone: +0021952322756

Email: wctsai@cycu.edu.tw

Taoyuan City, Taiwan, R.O.C.

\section{Abstract}

Nowadays, because of energy crisis, attention has grown for solutions to reduce dependence on fossil fuels. Companies started developing electric vehicles and sought to disrupt the market. Company A, as a new entrant, successfully developed a disruptive innovation of the world's first high-performance, zero emissions, and twowheeled electric scooter in 2015. Therefore, this study aims to explore the organizational engine for launching disruptive innovation project in traditional motorcycle industry by case study of company A. Following qualitative research method, this study concludes three main findings. First, a leader with heterogeneous background was important to propose a disruptive product concept, set a pioneer product strategy, and establish organizational culture supporting creativity. Second, challenging and ideal product concept could just be the stimulation for initiating dynamic product development process under the creativitymotivated culture. Finally, to support disruptive innovation, management team could take a more flexible and constructive attitude towards cost control issue.

\section{Keywords: Organizational Engine, Leadership, Disruptive Innovation Project, Product Development}

\section{Introduction}

Nowadays, climate change, energy shortage and greenhouse effect issues enhance the public awareness of environmental protection and accelerate the industrial development of green energy. Attention has grown for requirement to move toward innovation for more sustainable solutions and to reduce dependence on fossil fuels (Pinkse, Bohnsack, \& Kolk, 2014). One of the industries that has come to the fore distinctly is the automotive industry, where is expected with the internal combustion engine (ICE), low-emission vehicles (LEVs) or electric, hybrid, and fuel-cell vehicles (FCVs) to be substitutes for current fossil fuel consumption vehicles (Bakker, van Lente, \& Engels, 2012) to solve severe air pollution, one of main cause of global climate issues.

Scholars reveal that even with vast interest, because of existing manufacturers' centrality and dominant market shares, incumbents in the motorcycle industry consider electric vehicle as a whole new and relatively competitive product, which seems to defend their current product positions and business models, hence forming a high barrier to move forward (Kemp, Schot, \& Hoogma, 1998). Financial perspective is another factor which may be considered as the main role of influencing decision making. Markets in countries and industries are sophisticated, mature and progressively commoditized; achieving market share growth is relatively expensive. For most firms, new product development implies production line extensions, technology improvements, and product innovations, and should also aim to maintain market share (Cooper, 2011). The literature has indicated the innovation process as a pricey and risky one, since organizations have to invest in research \& development, training, and production operation, and the outcome is uncertain (Goedhuys, 2007). Therefore, as market size remains, companies increasingly compete for the market share by introducing insignificant but cost-saving new products one after another. In mature markets, the launch of a fully differentiated new product is rare these days (Cooper, 2011). 


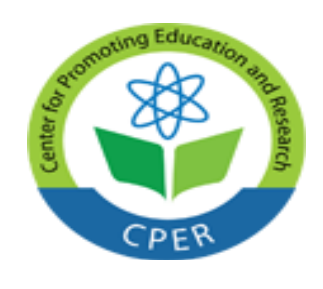

However, company A is recognized as a new entrant to the market and launched disruptively innovative product of the world's first high-performance, zero emissions, and two-wheeled electric scooter in 2015. Company A also at the same time announced a battery swapping infrastructure that aims to promote and implement an efficient, clean and flexible energy use. Company A intends to become a technological leading company transforming the system connecting sustainable energy and urban transportation. Unlike existing elder-aid electric scooters in current market, company A provides their first series battery-swapping electric scooter with $95 \mathrm{~km} / \mathrm{hr}$ top speed, acceleration of 0 to $50 \mathrm{~km} / \mathrm{h}$ in 4.2 seconds, and range of $>100 \mathrm{~km}$ when traveling at speeds of $40 \mathrm{~km} / \mathrm{h}$ which are consider as highly competitive to current main stream fossil-fuel powered scooters. Furthermore, it is marketed with its smart, highquality and high-tech features of smart-phone Bluetooth connection, programmable LED headlight, 30 on board detecting sensors, customized sounds and light sequences of the headlights and taillights, aluminium liquid cooled permanent magnet synchronous motor, and ultra-lightweight aluminium monologue chassis.

With innovated technology, high performance and unique design of scooter, company A's market share was more than $92 \%$ in Taipei and New Taipei City. According to company A's press release, in two and half year, there are more than 50,000 electric scooters sold from company A, 150 million kilometers ridden by customers, 500 company A's battery swapping stations deployed across Taiwan, more than 25,000 battery swaps per day, 9 million total batteries swapped, and nearly 14 million kilograms less $\mathrm{CO}_{2}$ emitted. With record-high of sales by the end of 2017, Company A reached 4.4\% market share in Taiwan domestic scooter market which secured company A's position as the nation's top electric scooter maker. Aside from breaking the company's record, this figure represents a record-high of electric scooter sales number in Taiwan as well.

Copious industries are influenced by technologically less sophisticated and market-driven innovations, but disruptive innovations are increasingly important both in high-tech industries and traditional industries (Assink, 2006; Christensen, 1997). Second, extant research focuses mainly on problems impeding and interfering incumbents from responding effectively to unpredictable disruptive changes (Markides, 2006). Little is known about the obstacles and opportunities new entrant firms encounter in developing disruptive innovation (Habtay, 2012). The purpose of this study is, therefore, to explore the organizational engine for successfully launching disruptive innovation project in traditional motorcycle manufacturing industry by case study of company A, which is a new entrant firm found and led by a CEO from high-tech industry.

\section{Literature Review}

\subsection{Disruptive Innovation}

Under current dynamic business environment, which is outlined with rapid technological shift, product life cycles shortening, and globalization, innovations are considered as crucial to a firm's survival and growth (Chen, Tang, Jin, Xie, \& Li, 2014). Accordingly, innovation has fostered significant interest among management practitioners and has become an important research topic. With reviews of empirical literature, Yu and Hang (2010) indicated that Disruptive Innovation Theory, popularized by Christensen (1997), has been revealed as strategically crucial in practice. According to Christensen (1997), by different enterprise innovation scenarios, innovation can be divided into two innovation patterns: Sustaining Innovation and Disruptive Innovation. Disruptive innovators rearrange market combination and create new value by identifying and creating new market segments or renovating existing market.

Christensen and Raynor (2003) pointed out two different innovation entries, which are low-end disruption and new-market disruption. When exiting products or service is over-achieving consumers' requirements and expectation with relatively higher cost, low-end disruption might be identifying to provide lower-pricing products or services by delivering simple and clear message and functions which would fit customers' need. Secondly, when current product characteristic can't attract potential customers, or consumer behaviour is limited by inconvenience or insufficiency, new-market disruptive innovation could stimulate the market activeness. 


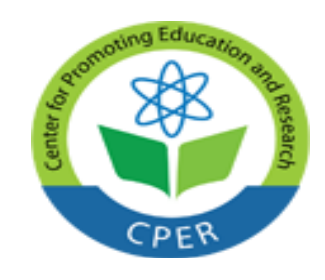

Disruptive innovation has been emerged as a product or service significantly altered and improved in ways that the market did not expect by discovering new categories and segments of customers, or lowering costs and enhancing quality of consumer requirements in the existing market. Disruption does these partly by harnessing new technologies but also by developing new business models and exploiting old technologies in new ways. Moreover, Yu and Hang (2010) also reveals that new entrant firms have benefits and superior opportunities of success in disruptive innovations, which are differentiated from established companies, due to their smaller scale, shorter company histories, and relatively light commitments to value chains and current technological practices (Macher \& Richman, 2004).

Disruptive innovation theory has cultivated a powerful influence on management practices and aroused plenty of rich debate within academia (Yu \& Hang, 2010). Markides (2006) argued that different kinds of innovations entail different competitive effects and generate different kinds of markets, which should be considered as distinct phenomena. For example, business-model innovations and radical (new-to-the-world) product innovations were classified as disruptive technological innovations by Markides (2006). Firstly, Markides (2006) addressed that businessmodel innovation is discovered as a radically unique business model in an existing business. Two identical characteristics were indicated that (1) New customers (who are distinct from those existing competitors focus on) will be attracted by the new business models; And, (2) different from incumbents' current supply-chains, new and conflicting value-chains will be required by new business models in the industry (Pohl \& Elmquist, 2010). Furthermore, disruptive business-model innovations aim to enlarge the current economic pie by bringing new customers into market or by encouraging existing customers to join and accept the innovations (Markides, 2006).

The second type of innovation, radical innovation, approaches to be disruptive to the existing companies and competitors by introducing new-to-the-world products that none of current products in the market can be considered as substitutes for. In addition, radical innovations are disruptive to customers and suppliers as well (Hill \& Rothaermel, 2003). Prevailing consumers' behaviours and habits will be disturbed broadly as radical innovations are providing unexpected products and value propositions. And the markets that radical innovations create will reconstruct the combinations of core inquiring competences and complementary assets that used to be those current competitors have built their success on. With observing on market behaviours, disruptive innovations are broken down into categories by Markides (2006) of business-model innovations and radical innovations, which pose fundamentally different challenges for established companies, and implicate different connections and meanings for managers.

\subsection{Leadership in Disruptive Innovation}

To move forward in the market with disruptive innovations, despite of innovation itself, leadership credits significant influence for the success (Chen et al., 2014). Company strategies formulated by management team and leaders are critical for disruptive innovation; moreover, the encouraging organizational climate and culture are concluded to be important drivers of innovation performance (Cooper, 2011). Therefore, it has been stated that leadership is the most crucial factors affecting innovation, which may be through leaders' influence on organizational characteristics, such as strategy, culture, structure, or resources, or through a direct effect of leaders' behaviours on employees' creativity and motivation (Gumusluoğlu \& Ilsev 2009). Leaders can facilitate their followers to promote higher levels of creativity at work, provide a supportive work environment for enriching creativity, and cultivate an organizational climate helping on principles for more creative processes.

Markides (2006) believes that eventual market winners with disruptive innovation not only capture time perfection for the entry into the market, but also compile a series of plans and actions that promote the growth of market from niche into mass market by, typically, making significant investments in developing scale economies, traveling down learning curves, exploiting strong brands, and controlling the distribution channels to the mass market. With all above, it will depend on company top management teams and leaders' strategy making. It has been 


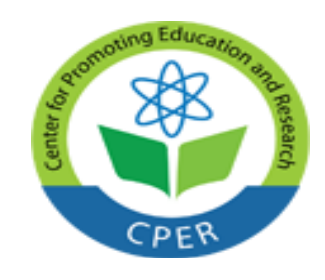

suggested that leaders have compelling impact on product innovation because compared to individuals, they take the significant weight on organizational and operational strategies decision-making (Chen et al., 2014).

The relationship between product innovation performance and transformational leadership has been emphasized in Chen et al. (2014) study. The result that corporate entrepreneurship and leadership are mediating the innovation process and impacting on product innovation performance has drawn attention on the focus of implementing transformational leadership practices among top management team who can create the innovative atmosphere which is considered as requirement to foster a company's product innovation performance. Furthermore, the study reveals that the appropriateness of leadership approach may be dependent on the target of the innovation during the fuzzy front end of the development process. Minimizing formal management processes and emphasizing the role of the individual by a leader is beneficial at the early idea generation stage where is aiming to discover the outcome with radical innovation. And to achieve a successful innovation approach, team leadership may be disclosed by enabling experimentation and extending the tolerance for risk taking and ideas failure trials (Robbins \& O'Gorman, 2015).

Studies show that when industrial new entrants to initiate and develop either disruptive technological, businessmodel or radical innovations, leadership with compelling impact has been addressed as an indispensable mediator and critical factor during innovation developing process. It further brings the topic for leaders to settle the connection of uncertainty due to different characteristics of new entrants to the industries. Habtay (2012) points out that when we consider the determining factors of entrepreneurial business model development within a company's relative disruption capacity and the distinct nature of disruptive innovation, new entrants and disruptive innovations are generally marked as homogeneous with indistinguishable disruptiveness potential. However, little comparative study further explores the relative disruptiveness potential and innovation process while industrial heterogeneity exists within one new entrant company.

\section{Materials and Methods}

To obtain insight information and details of the electric scooter project in Company A, a qualitative method, grounded theory, is applied in this study. Different from quantitative research, this study adopts the application of grounded theory for the following reasons: (1) In the characteristics of grounded theory, it contains the features of theory building (Corbin \& Strauss, 1998); (2) Grounded theory is optimal for qualitative theory development and methods implementation when research is focused on exploring contextualization and process orientations (Charmaz, 2006); (3) Meanwhile, grounded theory has also been described as the most scientific methodology in qualitative research methods. It combines the advantages of methodology such as deep interview, case study and field research. (4) From data collection perspective, grounded theory is superior to questionnaire experimental design, and content analysis (Corbin \& Strauss, 1998).

Regarding launching an innovation project, it brings attention to the composition of organizational participates. Company A, as a new entrant to traditional scooter manufacturer industry, is actually combined with high-tech and traditional industry human resources to achieve the goal of disruptive innovation. Unlike existing traditional scooter makers, company A is found and led by a CEO who served as a former chief innovation officer of a phone maker company with extensive experience in mobile phone technology. He brought the high-tech industry's essence and technology into traditional industry which hasn't been changed for years. Organizational members of Company A are also mixed with people from high-tech industry, like mobile phone companies, and from traditional industry, like automobile or motorcycle manufacturing companies, who should cooperate together as the innovation project proceeded.

The sampling logic of grounded theory follows the principle of theoretical replication different from the generalization logic pursued by Statistics, and it focuses on the richness of sample information, further constructs and interprets new theoretical framework. Theoretical sampling refers to sampling based on the concept that has been 


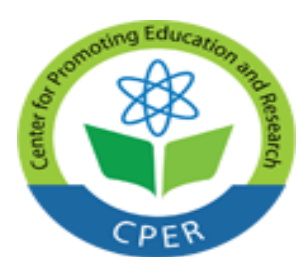

VOL: 5, ISSUE: 2

February/2019

E-ISSN: 2469-6501

CCenter for Promoting Education and Research (CPER) USA

WWW.cpernet.org

proved and formed to be relevant to the theory. According to theoretical sampling considerations, four qualified study subjects are identified as Table 1. They are core departmental managers participating in electric scooter project from the very beginning, which are the organizational members in charge of launching the project. In addition, to be more comprehensive, they are respectively the heads of RD team and management team with background from high-tech industry and traditional industry.

Table 1: Interviewee List with Background and Transcript Number

\begin{tabular}{|cclcc|}
\hline Interviewee & $\begin{array}{c}\text { Transcript } \\
\text { Number }\end{array}$ & $\begin{array}{c}\text { Position in } \\
\text { Company A }\end{array}$ & $\begin{array}{c}\text { Interview } \\
\text { Date }\end{array}$ & $\begin{array}{c}\text { Interview } \\
\text { Time }\end{array}$ \\
\hline A & Trad_PM & $\begin{array}{l}\text { Mechanical } \\
\text { Project Manager }\end{array}$ & 2017.06 .11 & $1: 39: 07$ \\
\hline B & Trad_RD & $\begin{array}{l}\text { Mechanical R\&D } \\
\text { Head }\end{array}$ & 2017.09 .26 & $1: 57: 57$ \\
\hline C & High-Tech_PM & $\begin{array}{l}\text { Electrical Project } \\
\text { Manager }\end{array}$ & 2017.09 .22 & $1: 08: 48$ \\
\hline D & High-Tech_RD & $\begin{array}{l}\text { Electrical R\&D } \\
\text { Head }\end{array}$ & 2017.09 .25 & $1: 52: 10$ \\
\hline
\end{tabular}

\section{Results}

\subsection{Initiation of Disruptive Innovation}

In Company A, noticeable background of founder was captured with industrial heterogeneity inputting and outstanding innovation approach. As a new entrant to the motorcycle manufacturing industry, innovation disruptiveness was expediting stimulated with distinct characteristics of high-tech industry and creativity background. Without industrial boundary which was set by incumbents, innovation possibilities can be cultivated wildly to explore niche disruptiveness. It aimed to have innovation not only on the product design but also product unique functionality and the way it is used is totally different from the market incumbent and consumer behaviour, as shown in Figure 1.

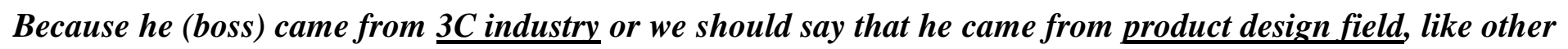
designers, they would have a lot of creativity. But if he didn't know much about the mechanical or the manufacture concepts, ideas would go wild. So, our mission is to conquer the mechanical and design issues when more and more creative and innovative ideas came from his mind with high standard for the product exterior design requirements. (Trad_RD_4)

What he (boss) was focusing on primary stage is like how to design and define a product to become cool and eye-catching. This is his expertise. (High-Tech_RD_4)

But you could see boss's clear ambitions of making our products unique and special from every design perspectives, no matter the mechanical design, motor design or ID. (High-Tech_RD_2)

During disruptive innovation initiation, besides the leadership, the strategy choice has massive impact for the success. Leaders and management team formulated company strategies for processing disruptive innovation and how to define the market with innovation. Strategy priority is clear in company A during the early stage of product development in order to accomplish disruptive innovation on the product and business. It focuses on the uniqueness rather than practicality in order to disrupt the established market which still operates with traditional methods and principles, as shown in Figure 1. 


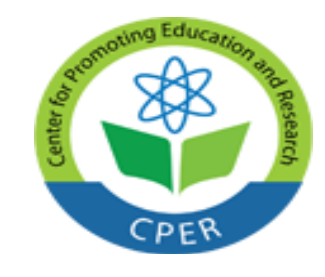

VOL: 5, ISSUE: 2

February/2019

E-ISSN: 2469-6501

CCenter for Promoting Education and Research (CPER) USA

WwW.cpernet.org

I have to say that most of time the priority was uniqueness over the practicality. That's because the product needs to be easy to recognized and striking on the road. I think, to certain extent, it is a decision and choice making on the strategy aspect. (High-Tech_RD_2)

It may also be true that because he (boss) made the first such special and unique product, he had a way to get so much attention in the market. If he did a lot of compromises from the beginning, maybe this brand will still be recognized, but perhaps its topicality may not be as much as it has now. (High-Tech_RD_6)

And for existing scooter makers, maybe it's because they would rely on suppliers' traditional technique and there was no one doing these kinds of functions before, so they will think those changes were difficult. (HighTech_RD_3)

In addition, company A believed that with disruptive innovation which is new to the market, there were no precedents to apply and refer to and furthermore, market can be defined and shaped by the first entrant with disruptive innovation, as shown in Figure 1. With strategy priority setting for cultivating the disruptive innovation and goal of shaping and defining its own market without following incumbent's tracks, company A's "UniquenessOriented Strategy" was practiced firmly at the early stage of product development in order to preserve the key element and characteristic of disruptiveness.

At that time, boss actually said that there was no need to do market survey, because the market may be defined by us. (High-Tech_RD_1)

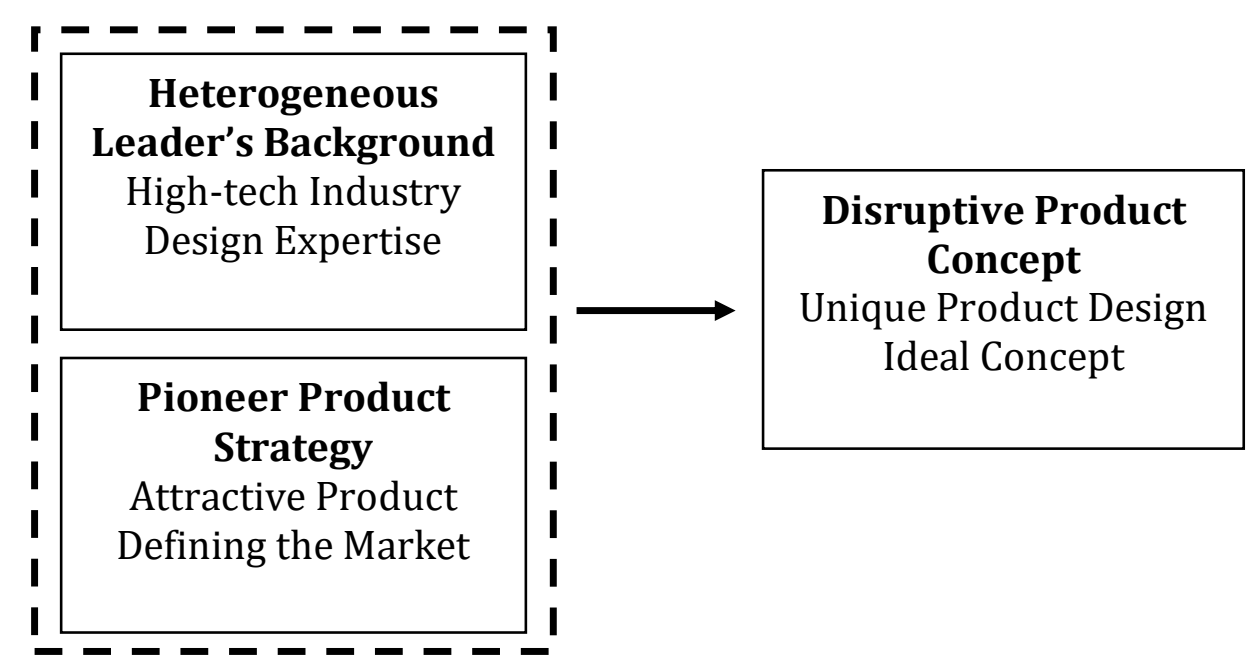

Figure 1: Formation of Disruptive Product Concept

With leader's background and strategy priority, creativity is highly encouraged and motivated in company A. Unlike existing companies with standard process and product market positioning principles, company A's leader encourage team members with creativity inspiration because of his background and strategy which are in favor of innovation, as shown in Figure 2.

Since boss was providing space for us to try new ideas, in this case, we would just go for it. Maybe we would encounter more failures than before, but if one of them succeeded, it could be one of disruptive innovations. (Trad_RD_2)

On the other hand, here, we got opportunities and time and we were asked for true differences from others. And most importantly, these unique ideas could be implemented. So, here, more innovation can be created and developed. $\left(T r a d \_R D \_3\right)$ 


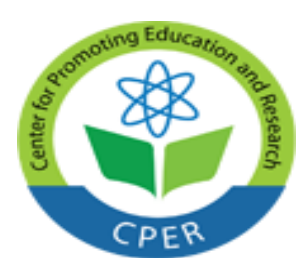

VOL: 5, ISSUE: 2

February/2019

E-ISSN: 2469-6501

(C) Center for Promoting Education and Research (CPER) USA

WWW.cpernet.org

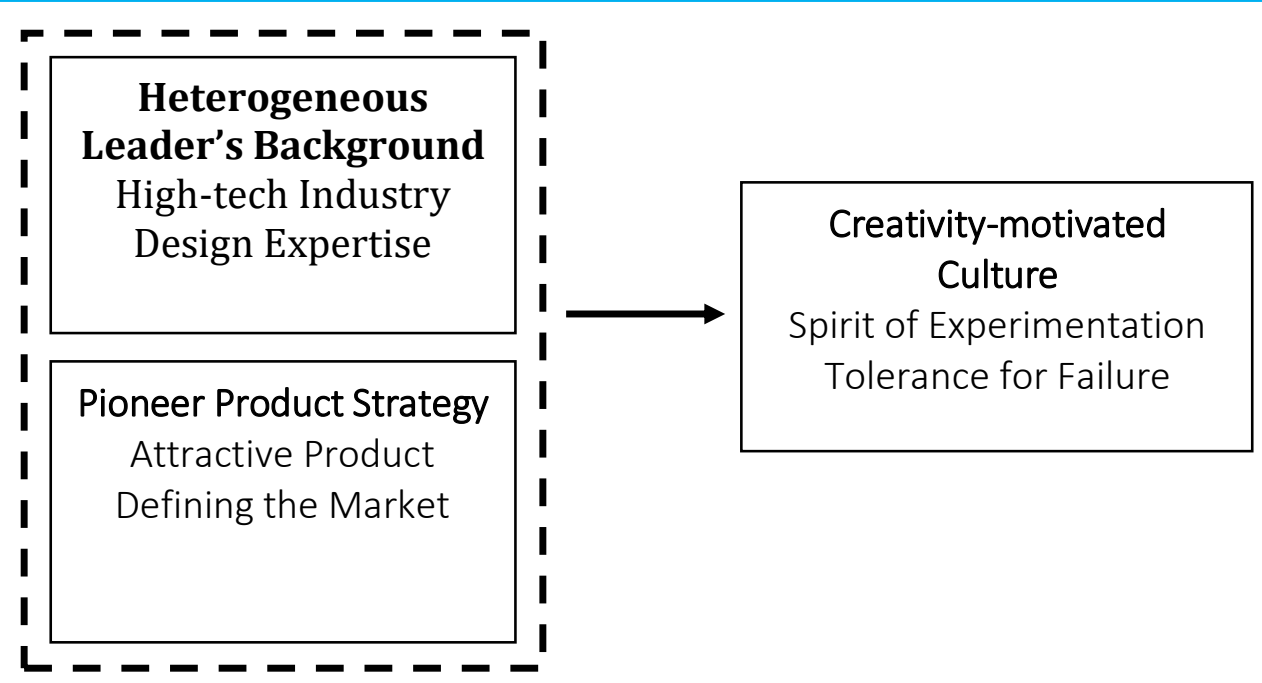

Figure 2: Cultivation of Creativity-motivated Culture

\subsection{Product Development Process}

Disruptive innovation occurs with distinct characteristics, technologies or business models different from existing ones in current market. Company A broke the "normal" or "standard" product innovation steps that were established for years in traditional motorcycle manufacturing industry and two-wheel vehicle market. During innovation initiating, no precedent can be referred or followed and even an identical differentiation can be set strategically as principle as it starts. Therefore, Company A did not set clear instructions on product design at the preliminary stage, but rather started from a sketchy idea. Company A set up the unique strategy and concept and introduced a new business and product systems to the market, as shown in Figure 3.

I have to say that most of time the priority was uniqueness over the practicality. That's because the product needs to be easy to recognized and striking on the road. I think, to certain extent, it is a decision and choice making on the strategy aspect. (High-Tech_RD_2)

Actually, I don't think it was planned so comprehensively and also that's because it is a unique product and business model that no one did it before. It was not easy to plan and think it thoroughly when there is no example or reference. (High-Tech_RD_2)

In the general industrial process, companies would define the explicit product positioning, cost and appeals in the product planning stage. The information collection and analysis for the planning reference are based on the experience or data in previous market and products, and certain specifications will be defined in the early stage. In contract, with ideal of fertilizing the innovation, Company A created another path for seeking and developing the disruptiveness incubation without following the established process and steps. Company A focused on product uniqueness of design and functionality with the overall framework which create large space for $R \& D$ to develop details. Without specific plan of product detail design, Company A operated with flexibility on product definition to enhance creativity and innovation, as shown in Figure 3.

There was no clear planning stage in this company. In previous company or working experience, in planning stage, product positioning, cost, MSRP, and product characteristics ...etc would be identified clearly first. However, in this company, there were no evident plans or principles in this stage. Product positioning, product cost or product feature requirements were not clarified at that time. The only focus would be the product appearance design. (Trad_PM_1) 


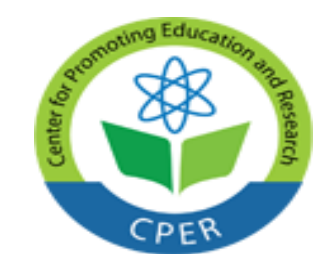

VOL: 5, ISSUE: 2

February/2019

E-ISSN: 2469-6501

CCenter for Promoting Education and Research (CPER) USA

WwW.cpernet.org

In current company, here, at the beginning, we only knew that we got a program but many product or module details were not identified yet. It was unusual oppositely that $\underline{R D \text { would feedback and defined back to the }}$ specification setting as designing was processed first before any detail product specification was set. (HighTech_PM_1)

Several years of experience in previous industry was forming the way we think and design, but here, we did not have to follow the way we used to think. Then it was kind of pushing us to think out of box and try to use different way to differentiate from those traditional ones. (Trad_RD_1)

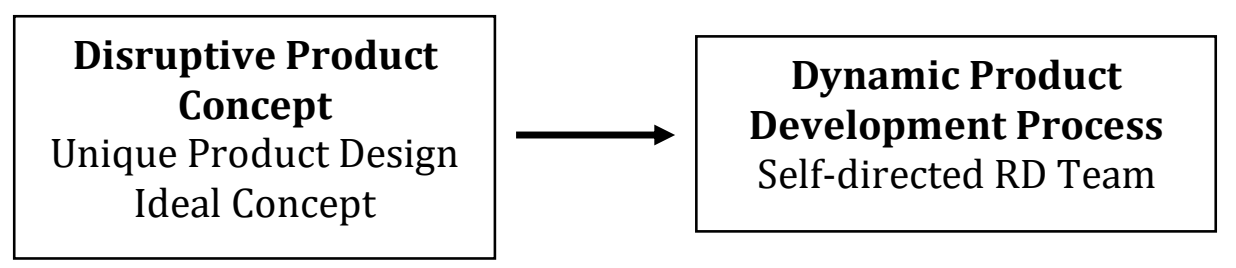

Figure 3: Demand for Dynamic Product Development Process

During innovation initiation, certain processes and the way of thinking in product development process were different from existing procedures or development concepts in order to fertilize the disruptive innovation. Within an organization, team members are the front line practicing and encountering the difference from their previous working experience. In company $\mathrm{A}$, regarding to the innovation and difference, RD team members are motivated and stimulated with more possibilities of innovation by the principle that company A's leader set, as shown in Figure 4. With optimistic attitude around team members, innovation was realized gradually by members and new principle and uniqueness-oriented strategy were adopted to accomplish disruptiveness.

Previously scooter light controller was mostly designed in the light system, so you can see that scooter headlights are always big ones. However, for us, as I mentioned, our product external appearance was defined and confirmed at very beginning and we can't change it. So, we got really limited space for the lighting system and there is nearly no space for the controller. At the end, EE team and our team figured out one solution that we separate and move the lighting controller out of lights and we can design and manage the controller by ourselves. Just like a disconnect-type, one of its advantages is that we can control our light directly and our light can have "breathing pattern" or other patterns which traditional ones can't do. (Trad_RD_5)

Our scooter is just like a huge cell phone which we already had external wireframe, and functionality is defined. So, we have to think how to utilize our design or material to fulfill those function requirements that issued by our boss. For example, we did mention that the handle lock would not work if our plastic part (appearance cover) could not be added with one more plastic bump. Of course, he (boss) rejected because the product external appearance design was our first priority principle and could not be modified. So, I started to think maybe there were some alternative ways without changing any appearance design. At that time, we were encouraged and motivated to design differently from traditional scooters and figured out some different mechanical structure finally.(Trad_RD_6)

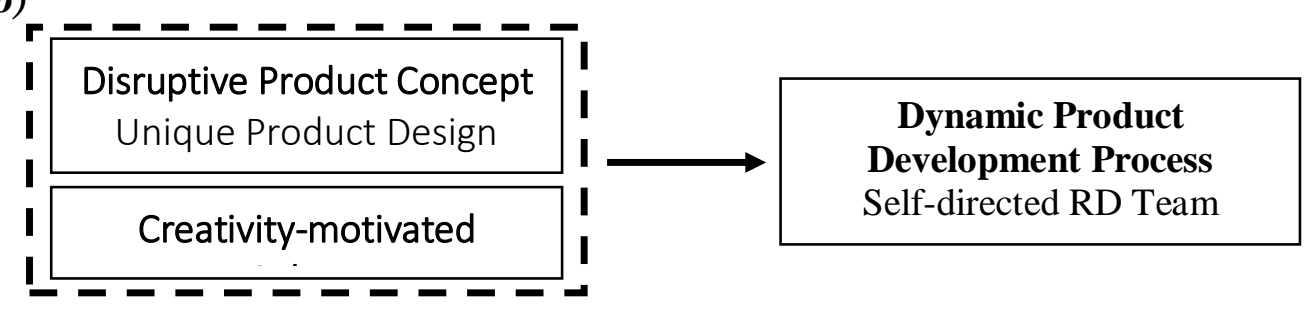

Figure 4: Promotion of Dynamic Product Development Process 


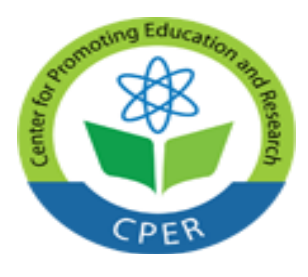

VOL: 5, ISSUE: 2

February/2019

E-ISSN: 2469-6501

CCenter for Promoting Education and Research (CPER) USA

WwW.cpernet.org

\subsection{Challenges of Cost Management}

To pursue uniqueness and disruptiveness of innovation, creativity-motivated culture for RD team members to explore ideas and experimentations and, at the same time, insufficient market demand at very beginning result in the cost control issues inevitably. In company A, "standard" or "normal" budgeting principals were not followed at the early stage of product development, but, instead, more dynamic and flexible cost management played a supporting role to make sure the innovation perfect and succeed, which would challenge the stability of project management, as shown in Figure 5. Scholars believe that financial constraint is one of barriers pursuing the innovation growth (Cooper, 2011), but also it is challenging for firms to unloose the control of R\&D expenditure.

But, in fact, at the very beginning, there were no completed engineering support and supplier chain behind this company. You wanted to create and produce a very unique product, but there were no sufficient demand as much as $3 C$ products. With uniqueness, you used special parts, and that means you had to start from tooling or manufacture new ones. But you didn't have enough quantity to amortize your cost. (High-Tech_RD_5)

The biggest difference is cost. From my previous working experience, product target cost will be settled firstly and follow with product specification development and planning. And then designer would understand the cost standard as starting designing products. But, in here, when every part or functionality of product were designed and developed, there was no clear target cost which further led to the situation that product design structure was added endlessly to pursue the perfect specifications to accomplish the goal of disruptive innovation. (Trad_PM_2)

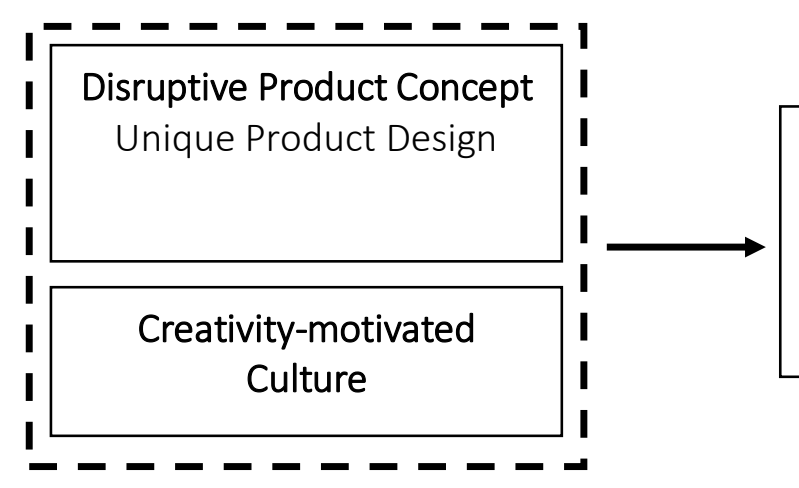

\section{Constructive Cost \\ Management}

Supporting Innovation

Flexible Control Process

Figure 5: Demand for Constructive Cost Management

\section{Discussion and Conclusions}

From the above case analysis and combining the information from Figure 1 to Figure 5, the organizational engine for launching disruptive innovation project can be conceptualized as three important interrelated conditions, which are energy accumulation in organization, provision of direction and proper environment and activated outcome of organizational dynamics, as shown in Figure 6. First of all, heterogeneous leader's background (high-tech industry and design expertise) and the pioneer product strategy (attractive product and defining the market) which is set by the leader create the basic beliefs, such as emphasis on product design, fundamentally different from those the incumbents are used to follow in the traditional industry. These beliefs form the essence of Company A and accumulate sufficient energy in organization for launching disruptive innovation project.

Second, because of the beliefs, disruptive product concept (unique product design and ideal concept) is proposed and creativity-motivated culture (spirit of experimentation and tolerance for failure) is also cultivated by the leader. A disruptive product concept is an extraordinary but ideal product goal derived from the design thinking of high-tech industry, which does not seem practical from the perspectives of traditional industry. This challenging product goal 


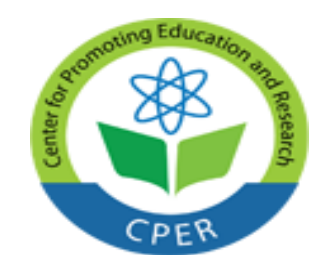

VOL: 5, ISSUE: 2

February/2019

https://ijbassnet.com/

E-ISSN: 2469-6501

(c) Center for Promoting Education and Research (CPER) USA

WwW.cpernet.org

provides a direction which organizational members make efforts to follow. In addition, creativity-motivated culture is an appropriate environment encouraging organizational members to take actions and explore the opportunities to reach the product goal, as shown in Figure 6.

Finally, because of energy accumulation in organization and with clear disruptive direction and proper environment, dynamic product development process (self-directed RD team and creative innovations) is achieved and constructive cost management (supporting innovation and flexible control process) is built to support the product development. Dynamic product development process is the demonstration of pursuit of disruptiveness by organizational members themselves without following traditional product development patterns, especially in RD team. For project management staff, they learn to play a constructive role in cost management to facilitate disruptive innovation, which is different from the traditional thinking of budget allocation and control. In other words, dynamic product development process and constructive cost management are the desirable activated outcome of organizational dynamics for disruptiveness, as shown in Figure 6.

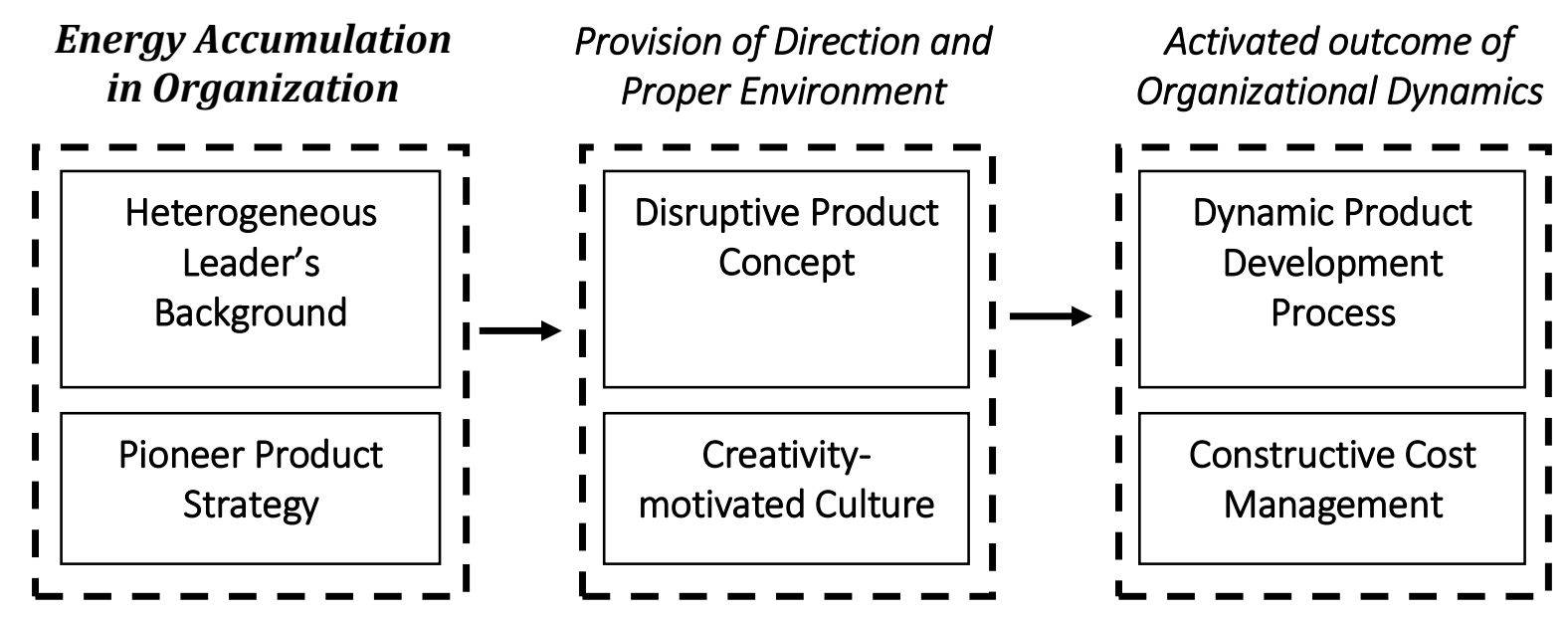

Figure 6: Conceptual Framework of the Organizational Engine for Launching Disruptive Innovation Project

In conclusion, launching disruptive innovation project is difficult not only for incumbents, but also for new entrants in an industry. From the case analysis of Company A, as a new entrant, a leader with heterogeneous background is important to break the rules of industry and proposes a disruptive product concept, set a pioneer product strategy, and also help to establish organizational culture supporting creativity. Furthermore, even though the disruptive product concept seems to be ideal, it can just be the stimulation for initiating dynamic product development process under the creativity-motivated culture. At last, in order to support disruptive innovation, it is important for management team to take a more flexible and constructive attitude towards cost control issue.

\section{REFERENCES}

Assink, M. (2006). Inhibitors of disruptive innovation capability: a conceptual model. European Journal of Innovation Management, 9(2), 215-233.

Bakker, S., van Lente, H., \& Engels, R. (2012). Competition in a technological niche: the cars of the future. Technology Analysis \& Strategic Management, 24(5), 421-434.

Charmaz, K. (2006). Constructing grounded theory: a practical guide through qualitative analysis. Thousand Oaks, CA: SAGE Publications. 


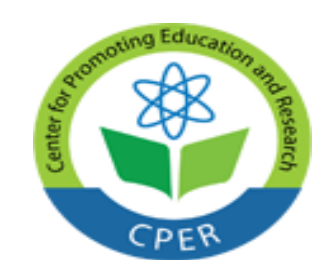

VOL: 5, ISSUE: 2

February/2019

https://ijbassnet.com/

E-ISSN: 2469-6501

(c) Center for Promoting Education and Research (CPER) USA

WwW.cpernet.org

Chen, Y., Tang, G., Jin, J., Xie, Q., \& Li, J. (2014). CEOs' transformational leadership and product innovation performance: the roles of corporate entrepreneurship and technology orientation. Journal of Product Innovation Management, 31, 2-17.

Christensen, C. (1997). The innovator's dilemma: when new technologies cause great firms to fail. Boston, MA: Harvard Business School Press.

Christensen, C., \& Raynor, M. (2003). The innovator's solution: creating and sustaining successful growth. Boston, MA: Harvard Business School Press.

Cooper, R. G. (2011). Perspective: the Innovation dilemma: how to innovate when the market Is mature. Journal of Product Innovation Management, 28(s1), 2-27.

Corbin, J. M., \& Strauss, A. (1998). Basics of qualitative research: techniques and procedures for developing grounded theory. Thousand Oaks, CA: Saga Publication.

Goedhuys, M. (2007). Learning, product innovation, and firm heterogeneity in developing countries: Evidence from Tanzania. Industrial and Corporate Change, 16(2), 269-292.

Gumusluoğlu, L., \& Ilsev, A. (2009). Transformational leadership and organizational innovation: the roles of internal and external support for innovation. Journal of Product Innovation Management, 26(3), 264-277.

Habtay, S. R. (2012). A firm-level analysis on the relative difference between technology-driven and marketdriven disruptive business model innovations. Creativity and Innovation Management, 21(3), 290-303.

Hill, C. W., \& Rothaermel, F. T. (2003). The performance of incumbent firms in the face of radical technological innovation. Academy of Management Review, 28(2), 257-274.

Kemp, R., Schot, J., \& Hoogma, R. (1998). Regime shifts to sustainability through processes of niche formation: the approach of strategic niche management. Technology Analysis \& Strategic Management, 10(2), 175-198.

Macher, J. T., \& Richman, B. D. (2004). Organisational responses to discontinuous innovation: a case study approach. International Journal of Innovation Management, 8(01), 87-114.

Markides, C. (2006). Disruptive innovation: in need of better theory. Journal of Product Innovation Management, 23(1), 19-25.

Pinkse, J., Bohnsack, R., \& Kolk, A. (2014). The role of public and private protection in disruptive innovation: the automotive industry and the emergence of low-emission vehicles. Journal of Product Innovation Management, 31(1), 43-60.

Pohl, H., \& Elmquist, M. (2010). Radical innovation in a small firm: a hybrid electric vehicle development project at Volvo Cars. R\&D Management, 40(4), 372-382. 


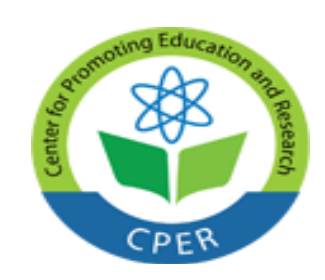

VOL: 5, ISSUE: 2

February/2019

https://ijbassnet.com/

E-ISSN: 2469-6501

(C) Center for Promoting Education and Research (CPER) USA

www.cpernet.org

Robbins, P., \& O'Gorman, C. (2015). Innovating the innovation process: an organisational experiment in global pharma pursuing radical innovation. R\&D Management, 45(1), 76-93.

Yu, D., \& Hang, C. C. (2010). A reflective review of disruptive innovation theory. International Journal of Management Reviews, 12(4), 435-452. 